\title{
CISPLATIN ENCAPSULATED IN VATERITE NANOPARTICLES FOR TARGETED DELIVERY AND SLOW RELEASE
}

\section{S. P. Dunuweera}

Abstract - Cisplatin is a commonly used anticancer drug which is the first generation of platinum-based anticancer drugs developed. The cis configuration enables the binding of the coordination complex to one or two DNA strand(s) and thereby crosslinking the DNA strands triggering the cells to die in a programmed manner. Cisplatin is administered to patients intravenously as a short-term infusion in normal saline for chemotheraputic treatment to solid malignancies. It is used to treat various types of cancers which include sarcomas and some carcinomas such as small cell lung cancer, ovarian cancer, lymphomas, bladder cancer, cervical cancer, and germ cell tumours. It is found that cisplatin is particularly effective against testicular cancer with a cure rate of $10-85 \%$. When administered into blood, cisplatin reacts with thiol containing proteins present in blood plasma thus reducing its bioavailability and increasing cytotoxicity. Cisplatin is associated with numerous side effects which include nephrotoxicity, nurotoxicity, nausea and vomiting, ototoxicity (hearing loss), electrolyte disturbance and haemolytic anemia. In order to increase the bioavailability and to reduce dosage and cytotoxic effects to healthy cells, we have encapsulated cisplatin in hollow nanoparticles of the vaterite form of calcium carbonate and studied the release kinetics of the drug in solutionds at different $\mathrm{pH}$ values. We found that the drug is released slowly and steadily in the $\mathrm{pH}$ values of cancerous cells ( $\mathrm{pH}$ range $5.00-6.00$ ) but not in the $\mathrm{pH}$ ranges exhibited by healthy cells ( $\mathrm{pH}$ range $7.00-8.00)$. In this communication, we describe the synthesis and stabilization of nanoparticles of vaterite, their characterization, encapsulation efficiency of cisplatin in them and the slow release kinetics of the drug at various $\mathrm{pH}$ values. This is a way forward for safe and convenient chemotheraputic route to various cancers.

Keywords-calcium carbonate nanoparticles, hollow and porous vaterite nanoparticles, cisplatin, encapsulation, targeted delivery, slow and steady release

\section{Introduction}

Cisplatin also known as cisplatinum, platamin, neoplatin, cismaplat [1-2] with the chemical formula of cisdiamminedichloridoplatinum(II) (CDDP) is a first generation of platinum coordination compound-based anticancer chemotheraputic drug that is used to treat different types of cancers including sarcomas, some carcinomas (e.g., small cell lung cancer, and ovarian cancer), lymphomas, bladder cancer, cervical cancer, [3-7] and germ cell tumours.

\section{S. P. Dunuweera}

Department of Chemistry, University of Peradeniya, Peradeniya 20400, SRILANKA
It is found that cisplatin is particularly effective against testicular cancer with a cure rate of $10-85 \%$. However, cisplatin is associated with numerous side effects which include nephrotoxicity, neurotoxicity, nausea and vomiting, ototoxicity (hearing loss), electrolyte disturbance and haemolytic anaemia [4-6]. Most of these side effects can be either reduced or overcome if cisplatin could be encapsulated in a suitable host material and directed towards cancer cells targeted manner and allowed to release only in minimum sufficient dose in uniform manner. When cisplatin is administered intravenously, it reacts with thiol containing proteins present in blood plasma forming toxic by-products [8]. These reactions also hamper the bioavailability of cisplatin thus requiring higher doses. In this research, we designed and developed a novel molecular template method for the synthesising and stabilizing hitherto thermodynamically unstable vaterite phase of calcium carbonate hollow and porous nanoparticles and characterized extensively. Anticancer drug cisplatin was encapsulated within these nanoparticles and again well characterized. The release kinetics of the drug in buffer solutions of $\mathrm{pH}$ in the range 5-9 was then studied. We found that the drug is slowly and steadily released in slightly low $\mathrm{pH}$ values in the range 5-6. This is the physiological $\mathrm{pH}$ range around cancer cells maintained due to increased acidosis at the vicinity of cancer cells. However, the drug is hardly released in neutral and slightly alkaline $\mathrm{pH}$ values prevailing in healthy normal cells. As such, our strategy is important in directing cisplatin to cancer cells in targeted manner for slow and steady release only at the vicinity of the cancer cells. This strategy minimizes both the dosage and side effects and drastically increases the bioavailability and efficacy of the drug.

\section{Experimental}

References hollow $\mathrm{CaCO}_{3}$ micro-spheres were synthesized with the reaction between $\mathrm{Ca}\left(\mathrm{CH}_{3} \mathrm{COO}\right)_{2}$ and $\mathrm{NaHCO}_{3}$ in a solvent mixture of $\mathrm{H}_{2} \mathrm{O}$ and EG. Solution A was a mixture of $\mathrm{Ca}\left(\mathrm{CH}_{3} \mathrm{COO}\right)_{2}(25.0 \mathrm{~mL}, 0.30 \mathrm{M}), \mathrm{H}_{2} \mathrm{O}(10.0 \mathrm{~mL})$ and EG $(50.0 \mathrm{~mL})$. Solution B was a mixture of NaHCO3 (50.0 $\mathrm{mL}, 0.30 \mathrm{M}), \mathrm{H} 2 \mathrm{O}(10.0 \mathrm{~mL})$ and EG $(50.0 \mathrm{~mL})$. Then, the solutions $\mathrm{A}$ and $\mathrm{B}$ were mixed quickly under stirring, at room temperature. Stirring was continued for further 24 hours and the resultant suspension was filtered. The solid mass obtained was washed with ethanol first and subsequently with distilled water and dried under ambient laboratory conditions. The material obtained was characterized for particle size distribution in suspension by Laser Light Scattering based Particle Size Analyser Morphology of the dried particles was studied through SEM images while purity and crystallinity together with crystallite size were determined by Powder X-ray Diffractometry. FT-IR Spectroscopic results complemented the XRD analyses. XRF spectrum only showed the presence of Ca since our XRF is only capable of detecting elements 
with atomic number greater than 13. In the encapsulation of cisplatin drug into the hollow $\mathrm{CaCO}_{3}$ micro-spheres $0.50 \mathrm{~g}$ of $\mathrm{CaCO}_{3}$ nanoparticles were dispersed $100.0 \mathrm{~mL}$ of cisplatin injection solution and kept stirring for 24 hours to facilitate cisplatin encapsulation. The encapsulation was confirmed by XRF analysis of the product after washing with copious amount of water and allowing to air dry under ambient laboratory conditions. Release kinetics was evaluated by placing the product dispersion in a dialysis bag and allowing to release into aqueous solutions at different $\mathrm{pH}$ values. The quantitative determination of the released drug was performed by analysing the platinum content in the external solution.

\section{Results and Discussion}

Particle size analysis shows that the colloidal solution contains particles of average size $35 \mathrm{~nm}$ with a size distribution in the range $25 \mathrm{~nm}$ to $50 \mathrm{~nm}$. It is intriguing to note that the molecular template method gives nanoparticles with such a narrow size distribution. This is probably due to the fact that ethylene glycol:water in 5:1 v/v ratio contains over 16:1 molar ratio and since both can form two intramolecular hydrogen bonds the molecular template cages formed would contain $\sim 16: 1$ ratio of ethylene glycol:water molecules giving rise to nearly fixed cavity size in the range from $25 \mathrm{~nm}$ to $50 \mathrm{~nm}$.

When the particles in suspension are filtered, washed with distilled water and allowed to air dry followed by calcination at elevated temperature ethylene glycol and water molecules are escaped and organic substances are combusted forming carbon dioxide and water vapour. As such, the dried and calcined particles have ample voids in them thus giving rise to hollow and porous morphology. In the process of drying and calcinatin, some particles are aggregated forming clusters which are spherical in shape since the original vaterite nanoparticles are also spherical in shape as can be seen from the SEM image given in Figure 1.

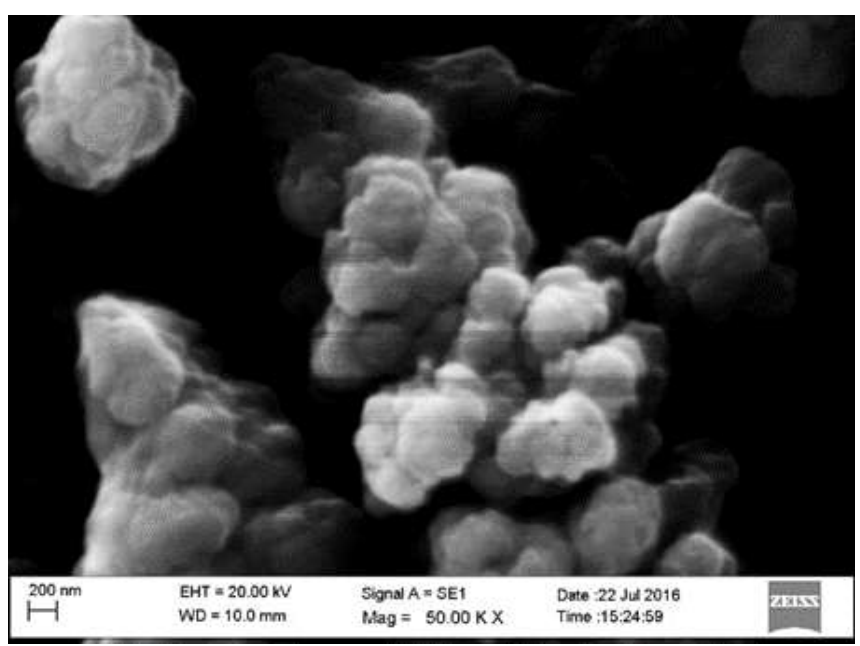

Figure 1: $\mathrm{SEM}$ image of $\mathrm{CaCO}_{3}$ nanoparticles synthesized by ethylene glycol:water molecular template method.

As indicated, the XRF spectrum shows the presence of only calcium and hence it gives some evidence towards ourity of the material at least to say that there are no appreciable amounts of element contaminants with atomic number greater than 13 .

As evident from the FT-IR spectrum, provided in Figure 2 (a), absorption bands at $877,745.8$ and $1084 \mathrm{~cm}^{-1}$ confirm the presence of the vaterite polymorph of $\mathrm{CaCO}_{3}$. This is further complemented by the spherical morphology of particles observed in sEM images. No absorption bands at $854,712,700 \mathrm{~cm}^{-1}$ and $848,714 \mathrm{~cm}^{-1}$ corresponding to aragonite and calcite, respectively, are present. Since vaterite is the most unstable form of $\mathrm{CaCO}_{3}$, it is very interesting that our procedure produces and stabilizes this unstable vaterite form rather than forming stable calcite form. The FT-IR spectrum of the encapsulated product obtained [Figure 2(b)] clearly show the presence of N-H stretching $\mathrm{N}-\mathrm{H}$ wagging together with $\mathrm{CO}_{3}{ }^{2-}$ vibrations. It also contains all the bands that are reported for hollow nanoparticles of $\mathrm{CaCO}_{3}$. In FTIR the absorption bands at $871 \mathrm{~cm}^{-1}$ shows the presence of vaterite polymorph.

Although XRF of the $\mathrm{CaCO}_{3}$ nanoparticles synthesized detects only $\mathrm{Ca}$ in our sample, the XRF of the cisplatin encapsulated $\mathrm{CaCO}_{3}$ product clearly shows the presence of $\mathrm{Ca}, \mathrm{Pt}$ and $\mathrm{Cl}$ with $\mathrm{Pt}: \mathrm{Cl}$ atomic ratio of the product is $1: 2$ showing that cisplatin is encapsulated within vaterite nanoparticles and that cisplatin maintains its identity in the confined environment also. Both FT-IR and XRF data suggest the encapsulation of cis-platin in hollow $\mathrm{CaCO}_{3}$.

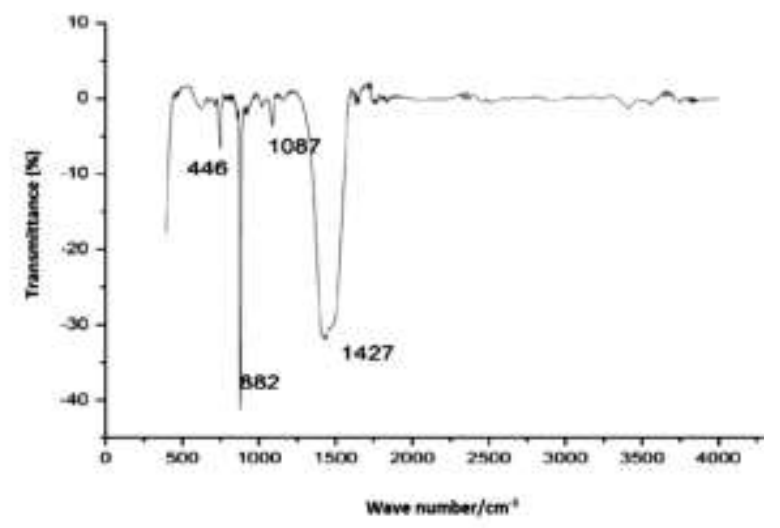

(a)

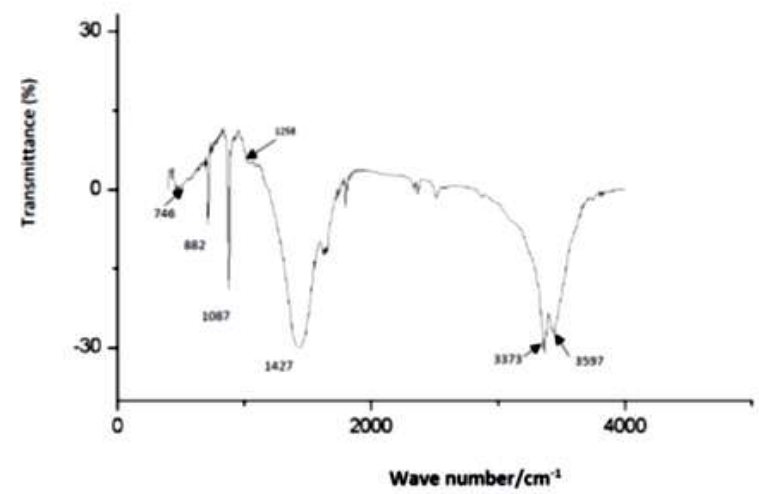

(b)

Figure 2: FT-IR spectrum of (a) $\mathrm{CaCO}_{3}$ nanoparticles prepared and (b) cisplatin-encapsulated $\mathrm{CaCO}_{3}$ nanoparticles. 
As can be seen from the XRD given in Figure 3(a), the sample contains basically vaterite as the major phase. A very small fraction of calcite particles can also be observed though the percentage abundance is negligible compared to that of vaterite nanoparticles. Application of the Debye-Scherrer Equation to the major XRD peak gives the crystallite size to be $28.0 \mathrm{~nm}$. This is very close to the average particle size obtained by the laser light scattering based particle size analysis. This may be the reason why both FT-IR and SEM techniques do not detect the calcite. The presence of a minute fraction of calcite is not surprising since it is the thermodynamically most stable phase of calcium carbonate and the presence of these nanoparticles have no adverse effect on the encapsulation of cisplatin.

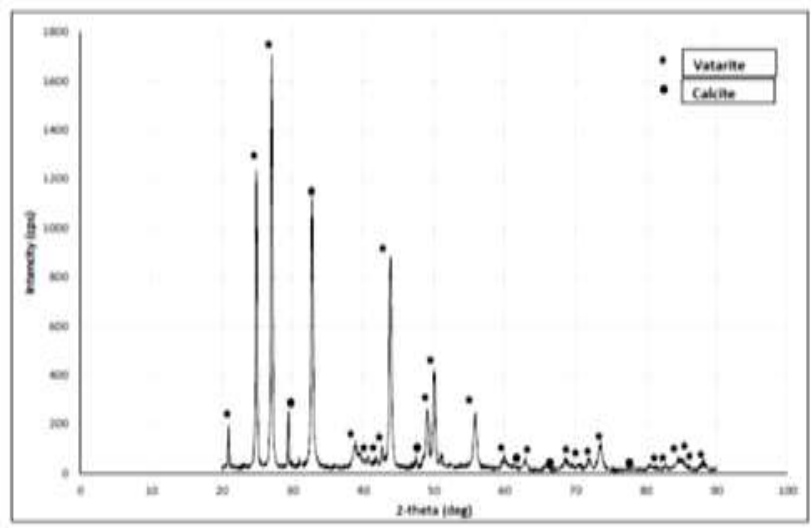

(a)



(b)

Figure 3: $\mathrm{X}$-ry diffractogrammes of (a) $\mathrm{CaCO}_{3}$ nanoparticles prepared and (b) cisplatin encapsulated $\mathrm{CaCO}_{3}$ nanoparticles.

Shown in Figure 4 is an SEM image of cisplatin encapsulated $\mathrm{CaCO}_{3}$ nanoparticles. The SEM images are quite similar to those obtained for vateite nanoparticles without cisplatin encapsulation. This shows that vaterite form of calcium carbonate is preserved even after the cisplatin encapsulation. It is interesting to note that the EDAX analysis does not show $\mathrm{Pt}, \mathrm{Cl}$ or $\mathrm{N}$ in the cisplatin encapsulated vaterite nanoparticles though XRF clearly shows the presence of $\mathrm{Pt}$ and $\mathrm{Cl}$ and FT-IR gives evidence to the presence of N. Both XRF and FT-IR are bulk analytical techniques that measure the composition of the bulk sample. However, SEM analysis is a surface analytical technique detecting a few micrometer width from the surface and therefore EDAX detects the elements present close to the surface of the vaterite nanoparticles. Since the elements of cisplatin cannot be detected within this depth of the surface and bulk techniques detect them it can be concluded that cisplatin is present deep inside the particles at least deeper than $1 \mu \mathrm{m}$ width from the surface. It is also intriguing that both the XRD and the light scattering based particle size analysis show $29 \mathrm{~nm}$ particle size the SEM show micrometer size particles. This is because in the absence of any protection these small nanoparticles attract to each other and form aggregates. When a large number of these nanoparticles assemble into aggregates cavities or hollow volumes are formed. These cavities act as hosts to reside cisplatin molecules. This is a clear evidence to prove that cisplatin is encapsulated in the centres of nanoparticles.

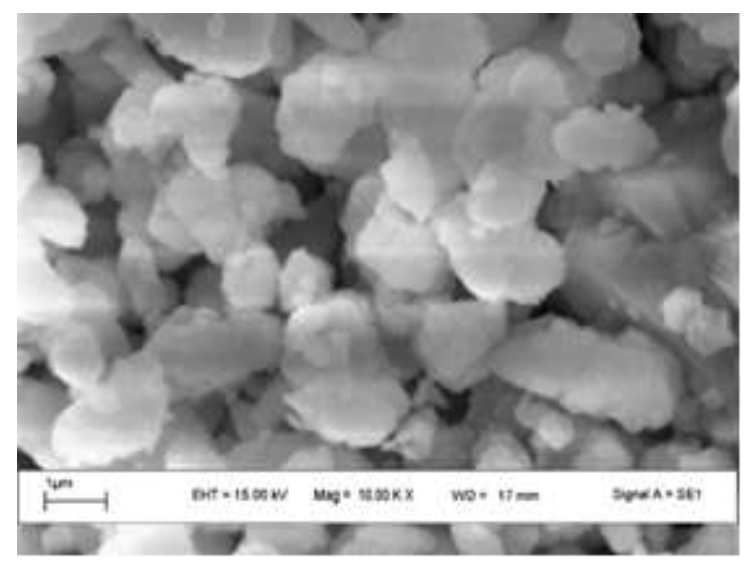

Figure 4: SEM image of cisplatin encapsulated $\mathrm{CaCO}_{3}$ nanoparticles.

Release kinetics of cisplatin in buffer solutions in the $\mathrm{pH}$ range from 5 to 9 is shown in Figure 5. Release kinetics of cisplatin encapsulated in vaterite nanoparticles in buffer solutions at different $\mathrm{pH}$ values show that there is hardly any release of cisplatin at neutral and basic $\mathrm{pH}$ values and the rate of release increases with decreasing $\mathrm{pH}$. At physiological $\mathrm{pH}$ of blood and that of healthy cells cisplatin is not released while at mildly acidic $\mathrm{pH}$ values of cancer cells cisplatin is slowly released.

\section{Conclusions}

Spherical and highly porous vaterite porous $\mathrm{CaCO}_{3}$ nanoparticles were synthesized using precipitation reaction of $\mathrm{NaHCO}_{3}$ with $\mathrm{Ca}(\mathrm{CH} 3 \mathrm{COO})_{2}$ in ethylene glycol-water medium with the aid of hydrogen-bonded network of cagetype, soft molecular templates. Cisplatin was successfully encapsulated in them to retain its chemical identity within the confined environment. The encapsulated product can be delivered to cancer cells in a targeted manner and the drug can be released in minimum and a constant sufficient dosage only at the vicinity of the cancer cells. 


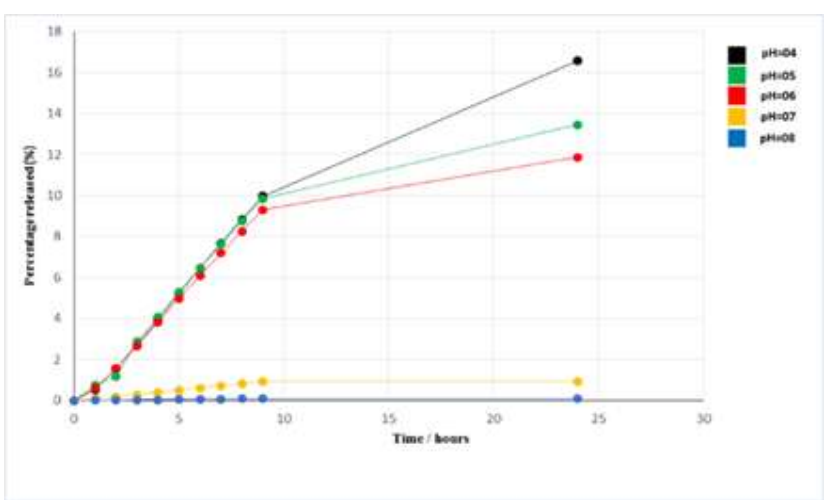

(a)

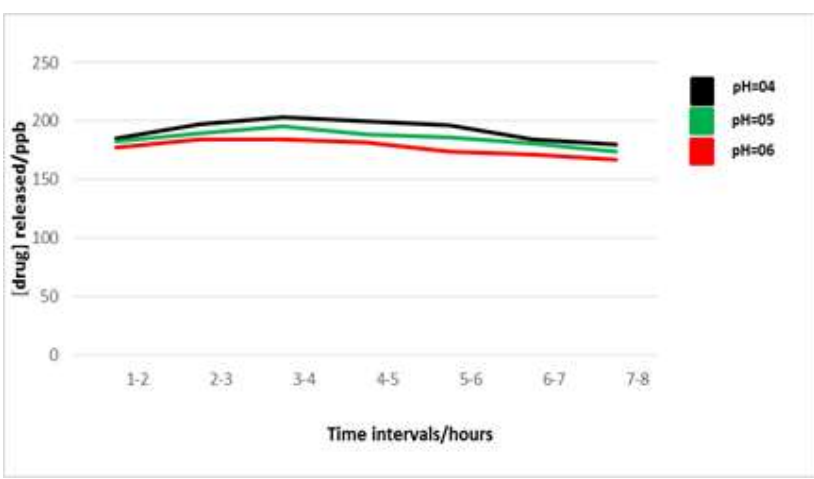

(b)

Figure 5: : (a) Anticancer drug release profiles in buffer solutions at different $\mathrm{pH}$ vakues as a function of time. (b) Concentrations of anticancer drug released in $\mathrm{ppb}$ for each different $\mathrm{pH}$ as a function oftime.

\section{References}

[1] L. H. Einhorn, "Treatment of Testicular Cancer: A New and Improved Model", Journal of Clinical Oncology, 8, 1777-1781, 2010. PMID 1700077.

[2] H. A Lieberman, L. Lachman, J. B. Schwartz, "Pharmaceutical Dosage Forms: Tablets", New York: Dekker. p. 153, 1990. ISBN 0-8247-8044-2.

[3] J. T. Hartmann, L. M. Fels, S. Knop, H. Stolt, L. Kanz and C. Bokemeyer, "A randomized trial comparing the nephrotoxicity of cisplatin/ifosfamide-based combination chemotherapy with or without amifostine in patients with solid tumors", Investigation of New Drugs, 18, 281-289, 2000.

[4] Hartmann J. T. and H.-P. Lipp, "Toxicity of platinum compounds", Expert Opin. Pharmacother. 4, 889-901, 2003.

[5] J. Sastry and S. J. Kelli., "Severe neurotoxicity, ototoxicity and nephrotoxicity following high-dose cisplatin and amifostine", Pediatr. Hematol. Oncol., 22, 441-445, 2005.

[6] I. Arany and R. L. Safirstein, "Cisplatin nephrotoxicity", Semin. Nephrol., 23, 460-464, 2003.
[7] T. Boulikas. "Poly(ADP-ribose) synthesis in blocked and damaged cells and its relation to carcinogen", Anticancer Res., 12, 885-898, 1992.

[8] A. I. Ivanov, J. Christodoulou, J. A. Parkinson, K. J. Barnham, A. Tucker, John Woodrow and P. J. Sadler, "Cisplatin Binding Sites on Human Albumin", The Journal of Biological Chemistry, 273, 14721-14730, 1998.

\section{About Author (s)}

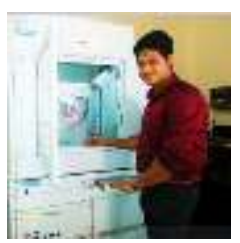

Mr. S. P. Dunuweera holds a B. Sc. Special Degree in Chemistry from University of Peradeniya, Sri Lanka, GCP. Psycholog. LIPs and PQHRM. He is Developing Synthetic Methods to Prepare Porous Nanoparticles to Encapsulate Anticancer Drugs for Targeted Delivery and Slow Release to reduce cytotoxicity of drugs to healthy cells, to increase bioavailability and efficacy of the drug, and to reduce drug dosage. As such, a New Era of Cancer Treatment is foreseen. $\mathrm{Mr}$ Dunuweera's research has been highlighted in a Discussion Forum of the ET: The Scholar of Sunday Times, The Sri Lankan Scientist Magazine and he has produced over publications/communications. 